\title{
Integrated Inventory Ranking System for Oilfield Equipment Industry
}

Jalel Ben Hmida, Siddharth Parekh, Jim Lee

University of Louisiana at Lafayette (United States)

jx69360@Llonisiana.edu,.sidman987@yahoo.com,.jlee@lonisiana.edu

Received: July 2012

Accepted: January 2014

\section{Abstract:}

Purpose: This case study is motivated by the subcontracting problem in an oilfield equipment and service company where the management needs to decide which parts to manufacture inhouse and which parts to purchase from suppliers when the capacity is not enough to make all required parts. A higher level quality can be achieved for the parts manufactured in house and the lead time can also be well controlled. Currently the company is making subcontracting decisions based on management's experience.

Design/methodology/approach: Working with the management, a Decision Support System (DSS) is developed to rank parts by integrating three inventory classification methods considering two quantitative factors including cost and demand, and one qualitative factor based on management experience. The proposed integrated inventory ranking procedure will make use of three classification methods: ABC based on cost, FSN based on demand, and VED based on management experience.

Findings: An integration mechanism using weights is developed to rank the parts based on the total priority scores. The ranked list generated by the system helps management to identify the most critical parts to manufacture in-house.

Originality/value: The integration of all three inventory classification techniques, covering both quantitative and qualitative factors, into a single system is a unique feature of this research. 
is important as it provides a more inclusive, big picture view of the DSS for management's use in making business decisions.

Keyword: inventory management, inventory classification methods, ABC, FSN, VED, subcontracting, decision support system

\section{Introduction}

Inventory management is important for the successful operation of most industries due to the amount of money inventory represents. Due to the variation in product demand, the industry may not be able to manufacture all the necessary parts on time. In this case, subcontracting becomes vital in order to avoid shortage and to maintain continuity in the manufacturing process.

Subcontracting is defined as "a situation where the firm offering the subcontract requests another independent enterprise to undertake the production or carry out the processing of a material, component, part or subassembly for it according to specifications or plans provided by the firm offering the subcontract" (Holmes, 1986). When the available capacity is not enough, a decision has to be made about what parts should be manufactured in-house and what parts should be subcontracted. The growing pressures of time-based global competition have led to the recognition of subcontracting as an important contributor to the competitive advantage of the firm (Kumar \& Wilson, 2009).

Manufacturing industries typically deal with thousands of parts and many suppliers. Extensive research has been done on the selection of suppliers or subcontractors (Krause, Handfield \& Scannell, 1998; Carr \& Pearson, 1999; Ferrer, 2003; Li, Murat \& Huang, 2009) and supplier uncertainty (Petrovic, Petrovic \& Rajat, 1998; Hillier 2002; Yang, Ronald \& Chu, 2005; Kim, Chatfield, Harrison \& Hayya, 2006; Mohebbi \& Hao, 2006). However, in-depth research in identifying which parts to manufacture in-house or subcontract is not common.

Several approaches have been used in the industries for make-or-buy decisions. The first approach is to manufacture the parts with early due dates and subcontract the ones that would not be possible to manufacture within the time frame. The problem with this approach is that the productivity of the plant decreases because different setups are used for different parts. Another approach that is being followed in the industries is to manufacture the parts that have similar setups to the part that is currently being manufactured, and subcontract the rest. Even though this approach increases the productivity of the plant, the inventory levels may go up (Atamtürk \& Hochbaum, 2001). 
The third approach is to prioritize the inventory by using general inventory classification methods. Inventory classification is a crucial element in the operation of any production company. Because of the huge number of inventory items in many companies, great attention is directed to inventory classification into the different classes, which consequently require the application of different management tools and policies (Chase, Jacobs, Aquilano \& Agarwal, 2006).

$A B C$ analysis is one of the most commonly employed inventory classification techniques. Conventional ABC classification was developed for use by General Electric during the 1950s. The classification scheme is based on the Pareto principle, or the $80 / 20$ rule, that employs the following rule of thumb: "vital few and trivial many." The process of $A B C$ analysis classifies inventory items into $A, B$, or $C$ categories based on so-called annual dollar usage. Annual dollar usage is calculated by multiplying the dollar value per unit by the annual usage rate (Cohen \& Ernst, 1988; Partovi \& Anandarajan, 2002). Inventory items are then arranged according to the descending order of their annual dollar usage. Class A items are relatively small in number, but account for the greatest amount of annual dollar usage. In contrast, class $\mathrm{C}$ items are relatively large in number, but make up a rather small amount of annual dollar usage. Items between classes $A$ and $C$ are categorized as class $B$.

Chen, Li and Liu (2008) examines several multiple criteria ABC analysis procedures which have been criticized for its exclusive focus on dollar usage. Other criteria such as lead-time, commonality, obsolescence, durability, inventory cost, and order size requirements have also been recognized as critical for inventory classification (Flores \& Whybark, 1987; Jamshidi \& Jain, 2008; Ng, 2007; Ramanathan, 2006). In order to accommodate multi-criteria inventory classification, many researchers have proposed methods that consider factors other than annual dollar usage. Flores and Whybark (1987) developed a cross-tabulation matrix method for use in bi-criteria inventory classification; they found that the method becomes increasingly complicated when three or more criteria are involved in evaluations. Flores, Olson and Dorai (1992) have proposed the use of joint criteria matrix for two criteria. Analytic hierarchy process (AHP) developed by Saaty (1980) has been successfully applied to multi-criteria inventory classification by Flores et al. (1992). The advantage of the AHP is that it can incorporate many criteria and ease of use on a massive accounting and measurement system, but its shortcoming is that a significant amount of subjectivity is involved in pairwise comparisons of criteria. They have used the AHP to reduce multiple criteria to one consistent measure. Hadi-Vencheh (2010) proposed a simple nonlinear programming model, which determines a common set of weights for all the items. Yu (2011) compared artificial-intelligence (AI)-based classification techniques with traditional multiple discriminant analysis (MDA).

Kabir and Hasin (2012) developed an improved multi-criteria inventory classification model using Fuzzy Analytic hierarchy process (FAHP) approach. Although the FAHP approach proved to be a convenient method in tackling practical multi-criteria decision making problems an 
improvement could be done in the determination of the weights of each component to handle uncertainties in the decision making.

Larson (1980) proposed a method FSN to classify parts as fast-moving (F), slow-moving (S) or non-moving ( $\mathrm{N}$ ) based on demand. Mukhopadhyay, Pathak and Guddu (2003) proposed VED method to classify parts as Vital (V), Essential (E), or Desired (D). The integration of ABC with other factors has been considered by several studies. $A B C$ is integrated with a mixed integer program (MIP) in Kirche \& Srivastava (2005) for order management. Bhattachaya, Sarkar and Mukherjee (2007) developed a procedure based on ABC and perishability of items. Hincapie, Lee and Emblom (2011) developed a decision support system which ranks component parts by integrating multi-criteria classification methods. The decision is to manufacture the parts that have the highest priority. Nahmias and Demmy (1981) modeled a system which maintains inventory to meet both high priority and low priority demands. They evaluated the control structure such that various methods of comparing refill rates may be developed both when rationing of the reorder point, quantity, and support level is and is not in effect.

Among the three general classification methods, ABC focuses on cost and FSN focuses on demand. Both $A B C$ and FSN are quantitative methods and do not take into account the perceived importance of the part in the eyes of the manager. VED allows the management to assign parts priority subjectively, but it does not fully utilize the available inventory data. The problem of these classification methods is that no one considers the integration of both quantitative (ABC and FSN) and qualitative factors (VED) in one model. An integrated approach needs to be developed that can rank the inventory based on multiple criteria, taking into account both quantitative and qualitative factors. Once this new approach is developed, a Decision Support System (DSS) can be implemented to rank the inventory. A DSS is defined as a class of information systems that support decision-making activities (Holsapple \& Whinston, 1996). Various DSS's have been developed for inventory management. Sadrian and Yoon (1994) developed a Procurement Decision Support System (PDSS) to improve the procurement practices of a company. Ronen \& Trietsch (1988) developed a DSS for purchasing components and materials for large projects taking into account lateness penalties. Walker (2000) developed of a decision support tool for the singleperiod inventory problem. DSS using simulation (Bed \& Nagarur, 1994), stochastic sampling (Jeong, Leon \& Villaboros, 2007), and fuzzy logic (Lan, Ding \& Hong, 2005; Zeydan \& Colpan, 2009) have also been developed to deal with various manufacturing applications, but none of these systems addresses the problem of ranking parts for subcontracting or manufacturing inhouse decisions using both quantitative and qualitative factors.

This case study is motivated by the subcontracting problem in an oilfield equipment and service industry. Currently the company is making subcontracting decisions based on management's experience without using any data, and discussion with the management indicates that both quantitative and qualitative factors are important. Our objective of this case study is to 1) develop an integrated inventory ranking procedure that takes into account both quantitative factors such as 
cost and demand, and qualitative factors such as functionality, efficiency, and manufacturing expertise or quality; and 2) develop a DSS to implement the integrated inventory ranking procedure and produce a ranked list to help the management in make-or-buy decisions.

The proposed integrated inventory ranking procedure will make use of three classification methods: ABC, FSN, and VED. Based on our discussion with the management and review of existing inventory data, we believe that the integration of the three methods will provide useful information to make subcontracting decision. At the same time, our DSS is designed in a modular fashion which can be modified to add more classification methods. Section 2 of this paper provides the logic we follow to implement each of the three inventory classification methods. Section 3 presents the integration mechanism and the theory foundation of our integrated procedure. The development of a DSS to implement our procedure is discussed in section 4. In section 5 , the case study is performed using real data from the oilfield equipment and service industry. Using the DSS, the company developed a ranked list of about 50 critical parts to be manufacture in-house. Our concluding remarks are given in section 6 .

\section{Inventory classification methods}

The proposed integrated inventory ranking procedure uses three classification methods: $A B C$, FSN, and VED. The ABC and FSN methods consider quantitative factors such as cost and demand, and the VED focuses on qualitative factors such as functionality, efficiency or quality. All the qualitative factors have cost implications. When the cost is difficult to estimate, VED allows management to subjectively assign a class based on past experience. An illustrative example of the application of each of these classification schemes in our research is given in the sections below.

\subsection{ABC classification}

The $A B C$ classification ranks the parts based on their dollar usage value in a given period. The high value parts (about 20\%) are classified as $A$, the middle value parts (about $30 \%$ ) are classified as $B$, and the lower value parts are classified as $C$. The procedure used in our study to perform the classification entails the following steps:

1. Compute quantity and dollar usage of each item from inventory data.

$$
\text { Dollar usage of each item }=\text { Quantity } * \text { Unit Cost }
$$

2. Arrange parts in descending order based upon the dollar usage values. 
3. Compute $\%$ of dollar value for each item.

$\%$ dollar value $=($ dollar usage value $/$ total dollar usage value $) * 100$

4. Compute \% quantity for each item.

$$
\% \text { quantity }=(\text { Quantity } / \text { Total quantity }) * 100
$$

5. Compute the cumulative percentages.

6. Classify the top $20 \%$ of the parts as A, the next $30 \%$ of the parts as B and the remaining parts as $\mathrm{C}$.

The cutoffs for $A B C$ in the procedure above are used as a general rule and the management may differ in the way they classify the inventory. So, the cutoff \% for classification should be based on user input. For example, in Table 1 part\#1 (6.45\%) is classified as A, part\#2 (32\%) classified as B and part\#3 (64.52\%) as C.

\begin{tabular}{|c|c|c|c|c|c|c|c|c|}
\hline Part\# & $\begin{array}{c}\text { Quantity } \\
\text { used }\end{array}$ & Unit cost & Total cost & $\%$ Cost & Cumulative \%cost & $\%$ Quantity & $\begin{array}{c}\text { Cumulative } \\
\% \text { Quantity }\end{array}$ & Class \\
\hline 1 & 10 & 200000 & 2000000 & $71.05 \%$ & $71.05 \%$ & $6.45 \%$ & $6.45 \%$ & $\mathrm{~A}$ \\
\hline 2 & 40 & 10000 & 400000 & $14.21 \%$ & $85.26 \%$ & $25.81 \%$ & $32.26 \%$ & $\mathrm{~B}$ \\
\hline 3 & 50 & 7000 & 350000 & $12.43 \%$ & $97.69 \%$ & $32.26 \%$ & $64.52 \%$ & $\mathrm{C}$ \\
\hline 4 & 20 & 1500 & 30000 & $1.07 \%$ & $98.76 \%$ & $12.90 \%$ & $77.42 \%$ & $\mathrm{C}$ \\
\hline 5 & 35 & 1000 & 35000 & $1.24 \%$ & $100.00 \%$ & $22.58 \%$ & $100.00 \%$ & $\mathrm{C}$ \\
\hline
\end{tabular}

Table 1. Example of ABC classification

\subsection{FSN classification}

With FSN, the parts having the highest demand (top 25\%) are classified as fast moving and the parts having the least demand (bottom 25\%) are classified as non-moving. The middle $50 \%$ of the parts are classified as slow moving. The FSN procedure used in our study to perform the classification involves the following steps:

1. Obtain the total demand for each part in a given period.

2. Arrange the parts in ascending order based on total demand.

3. Compute the first and third quartiles $\left(Q_{1}\right.$ and $\left.Q_{3}\right)$ from demand data.

4. Classify the parts using the following logic:

- If total demand $>\mathrm{Q}_{3}$ then Classify as Fast Moving

- If total demand $<\mathrm{Q}_{1}$ then Classify as Non-Moving

- Otherwise, Classify as Slow Moving 
In this classification, $\mathrm{Q}_{1}$ and $\mathrm{Q}_{3}$ are used as default values for the cutoffs. The final decision on the cutoffs should be based on management. An example of a FSN classification is shown in Table 2. Here we see that the fast moving parts are those parts that have a total demand over 600 , the slow moving parts are those parts having a total demand in between 400 and 600, and the non-moving parts are the ones with a total demand below 400 .

\begin{tabular}{|c|c|c|}
\hline Part\# & Total demand & Class \\
\hline 1 & 50 & $\mathrm{~N}$ \\
\hline 2 & 400 & $\mathrm{~S}$ \\
\hline 3 & 500 & $\mathrm{~S}$ \\
\hline 4 & 600 & $\mathrm{~S}$ \\
\hline 5 & 1700 & $\mathrm{~F}$ \\
\hline
\end{tabular}

Table 2. Example of FSN classification

\subsection{VED classification}

VED is based on the criticality of parts judged by the management where parts are classified as Vital, Essential, or Desirable. It can also be used for other aspects of decision making such as the due dates and setup times. This is a subjective decision made by the management and varies from part to part. In general, an item is classified as Vital in any of the following circumstances:

- Functionality: If the non-availability of the item shuts down the process completely and there is no standby unit as a spare.

- Efficiency: If the non-availability of the item completely reduces the efficiency of the manufacturing process.

- Quality: If the item is unique and/or the company involved is a world-class manufacturer of the item.

An item is classified as Essential in any of the following circumstances:

- Functionality: If the non-availability of the item shuts down the process but a standby unit exists.

- Efficiency: If the non-availability of the item reduces the efficiency of the process.

- Quality: If the quality of the item manufactured in-house is slightly better than purchased item.

An item is classified as Desirable in any of the following circumstances:

- Functionality: If non-availability of the item does not affect the operation of the manufacturing process 
- Efficiency: If non-availability of the item does not significantly affect the efficiency of the process.

- Quality: If the quality of the item manufactured in-house is no better than purchased item.

Once the three classifications are done, a method for combining them is needed. The different methods of combining the classifications along with their analyses are discussed in the next section.

\section{Integrated inventory ranking procedure}

In ranking the importance of parts, several factors must be considered. When three classification methods are integrated, it is possible that the management feels that the levels of importance of the three methods are different. Weights can then be assigned to the methods and they may change from one industry to the other. The integrated mechanism that this DSS introduces lets the user (i.e., management) decide what factors are of importance and in what order. So, if qualitative factors need to have higher priority than quantitative factors, higher weights need to be assigned to VED compared to ABC and FSN. Providing the management an option to choose which factor is most important in his/her scenario is a key design objective of our DSS. A good DSS also needs to have the flexibility and capability to answer "what if" questions.

While the factors considered in the classification methods are not mutually independent, the three classification methods may assign different priority scores to the same part, resulting in three different ranked lists. For example, if the part with the highest demand is the most expensive part, then both FSN and $A B C$ will assign the part with high priority. If the cost to make the part is relatively low but demand is high, then this part may not receive high priority based on ABC. A part with low demand and low cost may also be classified as "Vital" under VED if the quality of the part manufactured in-house is significantly better than purchased from subcontractor.

The notation that would be followed to indicate the priority levels for $A B C$, FSN, and VED classifications respectively is $[A B C, F S N, V E D]$. If we consider three priority levels for the purpose of integration, then a total of 27 different combinations $\left(3^{3}\right)$ are possible which can be generalized into 3 categories:

- Identical priority levels for all classifications (e.g., $[1,1,1]$ )

- Mixed priority levels for all classifications (e.g., $[1,1,2]$ )

- Distinct priority levels for all classifications (e.g., $[2,1,3]$ ) 


\subsection{Integration mechanisms}

\section{a) Identical priority levels for all classifications}

The priority levels assigned to each of the three classifications are identical. Assume that the weights assigned to each of the classifications is $(3,2,1)$, the parts with $(A, F, V)$ ranking will receive a priority score of $3 \times 3=9$. The parts in the lowest priority group $(C, N, D)$ will receive a priority score at $3 \times 1=3$. The priority scores that would be assigned to each of the different combinations of the three classifications are shown in Table 3. The 27 different combinations of the classifications have 7 different priority scores. If this mechanism is used to generate a ranked list, then many parts will have same priority scores resulting in a lot of ties. The management needs to break the ties in order to use the ranked list for decision making.

\begin{tabular}{|c|c|}
\hline Score & Classification \\
\hline 9 & $(A, F, V)$ \\
\hline 8 & $(A, F, E) ;(B, F, V) ;(A, S, V)$ \\
\hline 7 & $(A, F, D) ;(C, F, V) ;(A, N, V) ;(B, S, V) ;(A, S, E) ;(B, F, E)$ \\
\hline 6 & $(A, N, E) ;(A, S, D) ;(B, S, E) ;(B, F, D) ;(B, N, V) ;(C, F, E) ;(C, S, V)$ \\
\hline 5 & $(A, N, D) ;(C, F, D) ;(B, S, D) ;(C, N, V) ;(B, N, E) ;(C, S, E)$ \\
\hline 4 & $(C, N, E) ;(B, N, D) ;(C, S, D)$ \\
\hline 3 & $(C, N, D)$ \\
\hline
\end{tabular}

Table 3. Identical priority levels for all three classifications

\section{b) Mixed priority levels for all classifications}

In mixed priority levels, two of the three classifications have the same priority level, with the third classification either having higher or lower priority.

For illustration purpose, the two classifications $A B C$ and FSN are considered as having the same priority levels and are assigned the weights $(3,2,1)$. VED classification is assigned a higher priority level with weights of $(6,4,2)$. The priority scores that would be assigned to each of the different combinations of the three classifications are shown in Table 4. This integration mechanism will result in a ranked list that has less number of ties when compared to the identical priority levels case. Nonetheless, the management has to break the ties before using this mechanism to integrate the three classifications. 


\begin{tabular}{|c|c|}
\hline Score & Classification \\
\hline 12 & $(A, F, V)$ \\
\hline 11 & $(A, S, V) ;(B, F, V)$ \\
\hline 10 & $(B, S, V) ;(A, N, V) ;(C, F, V) ;(A, F, E)$ \\
\hline 9 & $(B, N, V) ;(C, S, V) ;(A, S, E) ;(B, F, E)$ \\
\hline 8 & $(C, N, V) ;(B, S, E) ;(A, N, E) ;(C, F, E) ;(A, F, D)$ \\
\hline 7 & $(B, N, E) ;(C, S, E) ;(A, S, D) ;(B, F, D)$ \\
\hline 6 & $(C, N, E) ;(B, S, D) ;(A, N, D) ;(C, F, D)$ \\
\hline 5 & $(B, N, D) ;(C, S, D)$ \\
\hline 4 & $(C, N, D)$ \\
\hline
\end{tabular}

Table 4. Mixed priority levels for all three classifications

\section{c) Distinct priority levels for all classifications}

For the sake of analysis, consider the classification having the highest priority level as having the weights $3 \times(3,2,1)$, the classification having the second highest priority level have the weights $2 \times(3,2,1)$, the classification that has the third and least priority level have the weights $1 \times(3,2,1)$. In this example, VED classification is given the highest priority level and therefore the weight assignment is as follows: $V \rightarrow 9, E \rightarrow 6, D \rightarrow 3$

$A B C$ classification is given the second highest priority level and therefore the weight assignment is as follows: $A \rightarrow 6, B \rightarrow 4, C \rightarrow 2$

FSN classification is given the third priority level and therefore the weight assignment is as follows: $\mathrm{F} \rightarrow 3, \mathrm{~S} \rightarrow 2, \mathrm{~N} \rightarrow 1$

The priority scores that would be assigned to each of the different combinations of the three classifications for this category are shown in Table 5. The ranked list generated by this integration mechanism will have 13 different priority scores for the 27 combinations.

Table 5 shows that ties are still taking place. Such ties can be broken off easily by simply taking into consideration the initial weighting factor arrangement. For the solution shown in Table 5, if VED > ABC > FSN, then the ranking will be as that shown in Table 6. 


\begin{tabular}{|c|c|}
\hline Score & Classiffication \\
\hline 18 & $(A, F, V)$ \\
\hline 17 & $(A, S, V)$ \\
\hline 16 & $(A, N, V) ;(B, F, V)$ \\
\hline 15 & $(B, S, V) ;(A, F, E)$ \\
\hline 14 & $(B, N, V) ;(C, F, V) ;(A, S, E)$ \\
\hline 13 & $(C, S, V) ;(A, N, E) ;(B, F, E)$ \\
\hline 12 & $(C, N, V) ;(B, S, E) ;(A, F, D)$ \\
\hline 11 & $(B, N, E) ;(C, F, E) ;(A, S, D)$ \\
\hline 10 & $(C, S, E) ;(A, N, D) ;(B, F, D)$ \\
\hline 9 & $(C, N, E) ;(B, S, D)$ \\
\hline 8 & $(B, N, D) ;(C, F, D)$ \\
\hline 7 & $(C, S, D)$ \\
\hline 6 & $(C, N, D)$ \\
\hline
\end{tabular}

Table 5. Distinct priority levels for all three classifications

\begin{tabular}{|c|c|c|c|c|c|}
\hline Ranking & Classification & Score & Ranking & Classification & Score \\
\hline 1 & $(A, F, V)$ & 18 & 15 & $(A, F, D)$ & 12 \\
\hline 2 & $(A, S, V)$ & 17 & 16 & $(B, N, E)$ & 11 \\
\hline 3 & $(A, N, V)$ & 16 & 17 & $(C, F, E)$ & 11 \\
\hline 4 & $(B, F, V)$ & 16 & 18 & $(A, S, D)$ & 11 \\
\hline 5 & $(B, S, V)$ & 15 & 19 & $(C, S, E)$ & 10 \\
\hline 6 & $(A, F, E)$ & 15 & 20 & $(A, N, D)$ & 10 \\
\hline 7 & $(B, N, V)$ & 14 & 21 & $(B, F, D)$ & 10 \\
\hline 8 & $(C, F, V)$ & 14 & 22 & $(C, N, E)$ & 9 \\
\hline 9 & $(A, S, E)$ & 14 & 23 & $(B, S, D)$ & 9 \\
\hline 10 & $(C, S, V)$ & 13 & 24 & $(B, N, D)$ & 8 \\
\hline 11 & $(A, N, E)$ & 13 & 25 & $(C, F, D)$ & 8 \\
\hline 12 & $(B, F, E)$ & 13 & 26 & $(C, S, D)$ & 7 \\
\hline 13 & $(C, N, V)$ & 12 & 27 & $(C, N, D)$ & 6 \\
\hline 14 & $(B, S, E)$ & 12 & & & \\
\hline
\end{tabular}

Table 6. Final classification ranks taking into account tie breaking procedure 


\subsection{Inventory ranking procedure}

Figure 1 depicts the integrated inventory ranking procedure. The user can choose to perform any of the classifications in any order. The ABC and FSN classifications are performed based on the cutoffs that are entered by the user while the VED classification is a subjective input from the management. Once the classifications are performed, the priority levels or weights need to be provided. This can be done in 27! ways for the 27 different combinations of the classifications and each choice can significantly affect the ranked list. In case the user does not want any classification to affect the decision-making procedure, the weights for that classification can be $(0,0,0)$. The parts are sorted in the descending order of their priority scores once they are calculated. The procedure does not suggest the weights and the user has the flexibility to assign them subjectively.

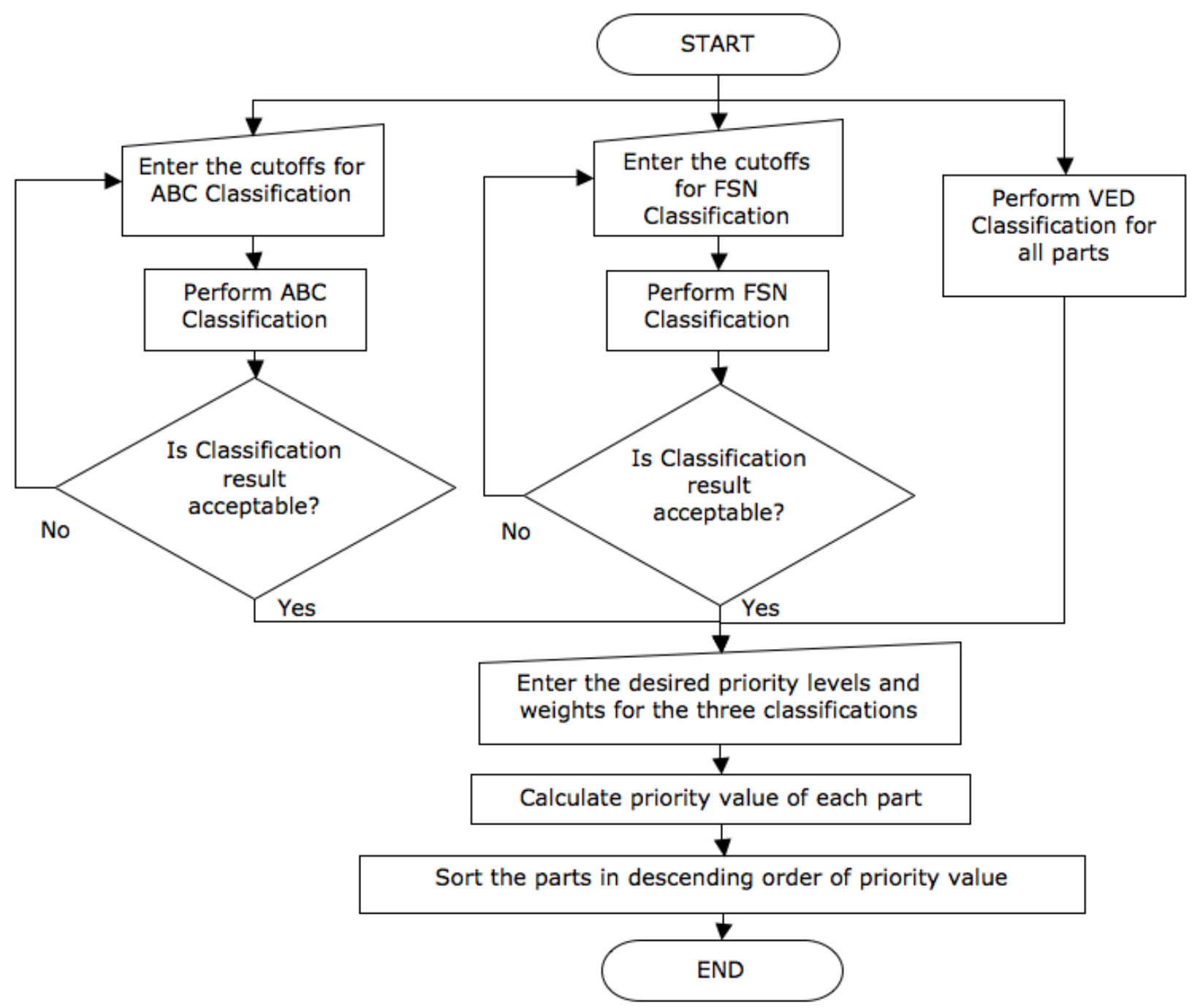

Figure 1. Integrated inventory ranking procedure flowchart 
Of the three classifications, we believe that the VED ranking system should have the most weight. If a part is so critical that it will shut down the entire process, then it should be given the highest priority over value and demand. The part's value, or ABC classification, should have the second rank in the weight system. If the part uses a significant amount of the manufacturer's capital to produce, it should be considered more important and have a higher rank than a high-demand part. However, if it is not vital to keep the process operating, then it should be ranked lower than a vital part. Lastly, the FSN classification can be used as a tiebreaker for high-cost, vital parts in the process. A high-demand part should have priority over a slow or non-moving part, but its demand should not take precedent over value or vitality.

Using above guidelines to assign weights to the three classifications will eliminate ties and satisfy some industry experts. This method can be used as an industry standard. There is no argument that a part which is vital to the process must take the highest priority; but one can argue that a fast-moving part should be prioritized over a high-cost part. The main idea of these guidelines is to use a multiplier to distinguish between the different classifications to eliminate ties altogether and have a clear ranking of inventory.

\section{Decision support system}

A DSS called Integrated Inventory Ranking System for Inventory Management (IRSIM) is developed in MS Access to implement the integrated inventory ranking procedure. IRSIM had three major modules: the database module, the model management module, and the user interface module. The database module and the model management module made up the internal design of IRSIM.

The internal structure of IRSIM is designed to be modular so changes can be implemented as desired. The model management module comprises of the code that was written to perform the classification techniques and to integrate them based on weights provided by the user. The development of the internal structure consists of designing the tables, defining the relationship among them, designing queries, writing programming modules and macros as depicted in Figure 2.

The user interface was designed to be as user friendly as possible, and the input that the system requires to perform the classifications was kept as simple as possible. Options have been provided in IRSIM to generate various other reports other than the reorder lists, so that the user can choose the kind of information he/she would like to use for making a decision. The validity of IRSIM is tested and verified by utilizing real world data. 


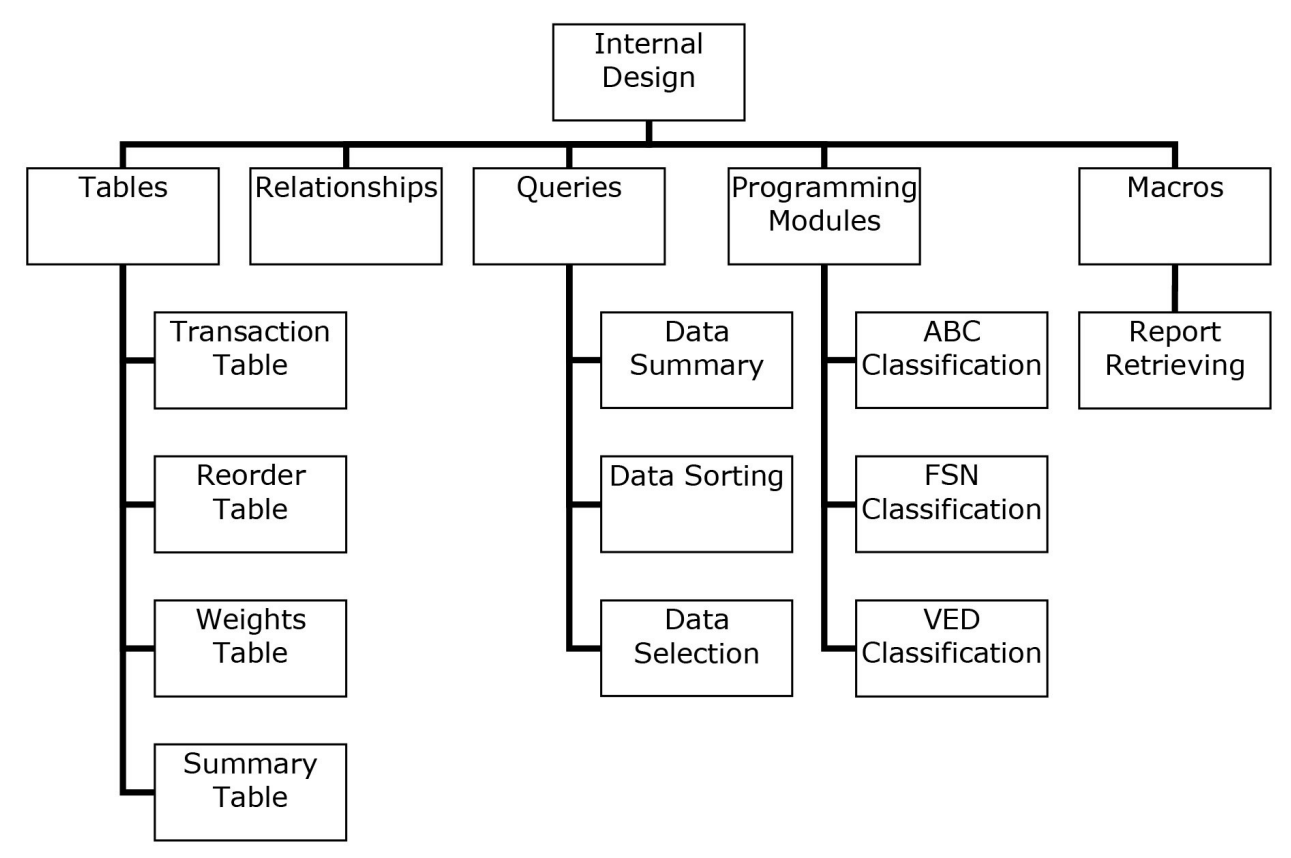

Figure 2. DSS internal structure

While we feel that VED is more important than $A B C$ and FSN, the weights may change from one industry to the other, so it is not practical to implement a general procedure to assign weights. It is possible that a relationship exists between the weights and the classifications, and the management can experiment different scenarios.

In the next section we use a case study to show the application of our tool in the real world. We believe that the proposed inventory ranking procedure is practical and flexible due to the fact that it gives the flexibility to a manager in deciding what factors are of utmost importance for their company and assign weights accordingly.

\section{Case study}

An oilfield service industry carries different types of inventories such as raw materials, purchased parts, partially completed goods, finished goods, tools and supplies. They have a total of 5,672 parts that they manufacture and another 5,663 different parts that they purchase. No matter how well they try to predict the demand for these, situations arise when the parts that are stored in the inventory are not enough to satisfy a customer's order. In such cases, the parts are put on a reorder table. An example of a reorder table is as shown in Table 7. It contains information such as the drawing number that needs to be used to manufacture the part, the current stock, the reorder point and the amount to reorder for each part. 
The reorder table consists of both the parts that can be manufactured and the parts that need to be purchased. Several times, all the manufactured parts that need to be reordered cannot be manufactured in time to meet the demand and these parts will then need to be subcontracted. A decision needs to be made about what parts in this reorder list should be manufactured in-house and what parts should be subcontracted.

For IRSIM to function, the input that is given should consist of the day-to-day transactions that take place in terms of demand. Some historical data are shown in Table 8. It consists of information such as the record number pertaining to a transaction, the part number, its description, the date and amount of demand, the price of each part and also information about the employee that placed the order. Once the data file is converted and stored in the transaction table of IRSIM, the user can then use IRSIM to perform the analysis.

\begin{tabular}{|c|c|c|c|c|c|}
\hline Part \# & Description & Drawing \# & $\begin{array}{l}\text { Quantity } \\
\text { in Stock }\end{array}$ & $\begin{array}{l}\text { Reorder } \\
\text { Point }\end{array}$ & $\begin{array}{l}\text { Reorder } \\
\text { Quantity }\end{array}$ \\
\hline 75007 & LUG, BACKING-7 5/8", 10 3/4", 13 3/8", 21" CASING TONG & 75007 & 12 & 25 & 100 \\
\hline 75012 & $\begin{array}{l}\text { HOUSING, MUB-5206 BEARING-7 5/8", } 10 \text { 3/4", \& 14" } \\
\text { TONG }\end{array}$ & 75012 & 19 & 25 & 100 \\
\hline 75014 & STUD, CAM-14" TONG & 75014 & 250 & 300 & 500 \\
\hline 75015 & ROLLER, CAM-14" TONG & 75015 & 272 & 300 & 500 \\
\hline 75035 & PIN, JAW HINGE-7 5/8, 10 3/4 \& 14" TONG & 75035 & 21 & 30 & 70 \\
\hline 75036 & PIN, JAW ROLLER-4 1/2" \& 5 1/2" - 10 3/4" TONG & CT-10-M012 & 5 & 15 & 25 \\
\hline 75037 & ROLLER, JAW-13 3/8" \& 13 3/8" HT \& 10 3/4" & CT-10-M015 & 4 & 25 & 50 \\
\hline 75065 & ROLLER, CAM-14" TONG & 75065 & 22 & 150 & 300 \\
\hline 75158 & ROLLER, DOOR-7 5/8" TONG & 75158 & 4 & 6 & 10 \\
\hline 75191 & PIN, SLIP HINGE; BJ 175 TON OR B+V 250 MT & 75191 & 2 & 8 & 10 \\
\hline 75195 & PIN, YOKE-175, $350 \& 500$ TON B J TOOLS & 75195 & 18 & 30 & 60 \\
\hline 75200 & ROD, LOCK FOR BJ $350 \& 175$ & 75200 & 0 & 10 & 20 \\
\hline 75206 & PLUNGER, OVERLOAD FOR BJ TOOLS & MISC. 190 & 26 & 45 & 100 \\
\hline 75220 & ROD, LOCK-500 TON BJ & 75220 & 1 & 3 & 6 \\
\hline 75318 & STUD, CAM-36" TONG / 21" CASING TONG & 75318 & 29 & 50 & 100 \\
\hline 75319 & ROLLER, CAM-36" TONG / 21" CASING TONG & 75319 & 45 & 50 & 100 \\
\hline 75557 & BODY, TONG DOOR INTERLOCK VALVE & 75557 & 17 & 25 & 50 \\
\hline 75558 & SPOOL, TONG DOOR INTERLOCK VALVE & 75558 & 17 & 25 & 50 \\
\hline 75561 & HOUSING, A-35 TONG UNLOADER VALVE & MISC. 425 & 11 & 25 & 50 \\
\hline 75562 & POPPET, A-35 TONG UNLOADER VALVE & MISC. 411 & 4 & 25 & 50 \\
\hline 75563 & SEAT, A-35 TONG UNLOADER VALVE & MISC. 412 & 5 & 25 & 50 \\
\hline
\end{tabular}

Table 7. Sample reorder table 


\begin{tabular}{|c|l|l|c|c|c|c|}
\hline Record\# & Part\# & \multicolumn{1}{|c|}{ Description } & Employee & Department & Quantity & Price \\
\hline 68496 & 60246 & INSERT, CASING SLIP - STRAIGHT TOOTH & 7400 & HAWKJAW & 1 & $\$ 39.50$ \\
\hline 68498 & 30034 & BOLT, U - NC & 6392 & MANUF USE & 4 & $\$ 0.65$ \\
\hline 68499 & 45301 & O-RING, BUNA N-90A & 7440 & PIPE \& FAB & 12 & $\$ 8.25$ \\
\hline 68501 & 77179 & $\begin{array}{l}\text { PIN, MASTER CYLINDER FRAMEMOUNTING } \\
\text { COMPONENT }\end{array}$ & 6165 & CAM & 2 & $\$ 6.52$ \\
\hline 68502 & 45303 & O-RING, BUNA N-70A & 7440 & PIPE \& FAB & 12 & $\$ 8.11$ \\
\hline 68505 & 45989 & O-RING, BUNA N-90A & 5394 & MANUF USE & 4 & $\$ 0.03$ \\
\hline 68507 & 45761 & $\begin{array}{l}\text { FITTING, TBG ADAPTER-NPT X TUBE X 90 } \\
\text { DEGREE }\end{array}$ & 5394 & MANUF USE & 12 & $\$ 3.44$ \\
\hline 68508 & 46059 & FITTING, ADAPTER-NPT RED BUSH-FLUSH & 5394 & MANUF USE & 4 & $\$ 0.96$ \\
\hline 68509 & 45996 & FITTING, ADAPTER-NPT X TUBE X 45 DEGREE & 5394 & MANUF USE & 4 & $\$ 5.44$ \\
\hline 68510 & 45936 & FITTING, ADAPTER-NPT X NPTF X 90 DEGREE & 5394 & MANUF USE & 6 & $\$ 1.35$ \\
\hline 68511 & 45528 & $\begin{array}{l}\text { FITTING, TBG ADAPTER-NPT X TUBE X 90 } \\
\text { DEGREE }\end{array}$ & 5394 & MANUF USE & 4 & $\$ 6.77$ \\
\hline 68512 & 45615 & FITTING, ADAPTER-NPT X TUBE & 5394 & MANUF USE & 4 & $\$ 1.51$ \\
\hline 68513 & 45937 & FITTING, ADAPTER-NPT X NPTF X NPTF X TEE & 5394 & MANUF USE & 2 & $\$ 4.80$ \\
\hline
\end{tabular}

Table 8. Transaction table

The steps that were followed to use IRSIM for performing analysis are as follows:

1) Select Parts - By clicking on the Select Parts function on the main menu of IRSIM, the transaction table was selected for parts having part numbers ranging between 75000 and 80000 . This selection automatically created the summary table and performed default classifications for $\mathrm{ABC}$ and FSN analysis.

2) Perform Classifications

a) VED Classification - Selection of the file and range led to the parts information page, where information about VED Classification was entered for each part. After entering information about the VED classification, the Perform $A B C$ and FSN Classification function was chosen.

b) $A B C$ Classification - The $A B C$ classification was performed by taking the \% of $A$ parts as $20 \%$ and $\%$ of $B$ parts as $30 \%$ with the rest of the parts classified as $C$. The result of this classification was as follows:

- Class $A \rightarrow 16.89 \%$ of the inventory accounts for $66.33 \%$ of the value

- Class $B \rightarrow 22.12 \%$ of the inventory accounts for $8.47 \%$ of the value

- Class $C \rightarrow 60.99 \%$ of the inventory accounts for $25.2 \%$ of the value 
c) FSN Classification -The FSN classification was performed by taking the $\%$ of $\mathrm{F}$ parts as $25 \%$ and $\%$ of $\mathrm{S}$ parts as $50 \%$ with the rest of the parts classified as $\mathrm{N}$. The result of this classification was as follows:

- Fast moving parts have a demand greater than or equal to 46

- Slow moving parts have a demand of less then 46 and greater than 5

- Non moving parts have a demand less than or equal to 5

3) Assign Weights - Once all the classifications were performed, they were assigned weights using the Assign Weights function on the main menu of IRSIM. The management of the oil equipment company believes that the costly parts should be made in-house, so $A B C$ is given the highest weights at $(10,5,1)$. The FSN is considered as more important than the VED, so a $(5,3,1)$ is used for FSN and $(3,2,1)$ is used for VED.

4) Generate Reorder Lists - To generate the reorder lists, the Reorder Lists function was selected from the main menu. A sample output is displayed in Figure 3 with the respective classifications and the priority scores.

Classification information for the parts in the reorder list

\begin{tabular}{|c|c|c|c|c|c|c|c|}
\hline Part No & Pant Description & Quantity & Price & $A B C$ & $F S N$ & $V E D$ & Prionity \\
\hline 75557 & BODY, TONG DOOR INTERLOCK VALVE & 258 & $\$ 30,441.42$ & A & $\mathrm{F}$ & Vital & 18 \\
\hline 75014 & STUD, CAM-14" TONO & 898 & $\$ 7,525.24$ & A. & $\mathrm{F}$ & Vital & 18 \\
\hline 75065 & ROLLER, CAM - 14" TONG & 906 & $\$ 4,158.54$ & A & $\mathrm{F}$ & Vital & 18 \\
\hline 75012 & HOUSING, MUE - 5206 EE,ARING -7 5.8", $1034 " \& 14 "$ TONG & 169 & $\$ 5,818.67$ & A & $\mathrm{F}$ & Essertial & 17 \\
\hline 75561 & HOUSING, A,35 TONG UNLOADER VALVE & 94 & $\$ 5,222.64$ & A. & $\mathrm{F}$ & E ssertial & 17 \\
\hline 75558 & SPOOL, TONG DOOR INTERLOCK VALVE & 269 & $\$ 3,838.63$ & A & $\mathrm{F}$ & E ssertial & 17 \\
\hline 75200 & ROD, LOCK FOR B.J $350 \& 175$ & 56 & $\$ 3,640.00$ & A & $\mathrm{F}$ & E ssertial & 17 \\
\hline 75220 & ROD, LOCK - 500 TON BJ & 35 & $\$ 3,850.00$ & A & $s$ & E ssertial & 15 \\
\hline 75037 & ROLLER, JMW - $1338^{\prime \prime} \& 1336^{\prime}$ HT \& $1034^{\prime \prime}$ & 300 & $\$ 2,970.00$ & B & $\mathrm{F}$ & Vital & 13 \\
\hline 75035 & PIN, JANN HINGE - $758^{\prime \prime}, 10344^{\prime \prime}$ \& 14 "TONG & 313 & $\$ 2,400.71$ & $\mathrm{~B}$ & $\mathrm{~F}$ & E ssertial & 12 \\
\hline 75195 & PIN, YOKE - 175, 350 \& 500 TON E.J TOOLS & 122 & $\$ 3,076.84$ & $\mathrm{~B}$ & $\mathrm{~F}$ & Desired & 11 \\
\hline 75318 & STUD, CAM - 36" TONG/21" CASING TONG & 230 & $\$ 1,904.00$ & $\mathrm{c}$ & $\mathrm{F}$ & Vital & 9 \\
\hline 75015 & ROLLER, CAM -14" TONG & 316 & $\$ 1,093.36$ & $\mathrm{c}$ & $\mathrm{F}$ & Vital & 9 \\
\hline 75319 & ROLLER, CAM - 36" TONG /21" CASING TONG & 202 & $\$ 1,020.10$ & $\mathrm{c}$ & $\mathrm{F}$ & Vital & 9 \\
\hline 75191 & PIN, SLIP HINGE; EJ 175 TON OR B \& V $250 \mathrm{MT}$ & 160 & $\$ 1,724.80$ & $\mathrm{c}$ & $\mathrm{F}$ & Essertial & 8 \\
\hline 75007 & LUG, EACKING - $75 / 8^{\prime \prime}, 103 / 4 ", 13$ 3/6", 21" CASING TONG & 121 & $\$ 1,569.37$ & $\mathrm{c}$ & $\mathrm{F}$ & E ssertial & 8 \\
\hline 75562 & P OPFET, A.35 TONG UNLOADER VALVE & 60 & $\$ 1,442.40$ & $\mathrm{c}$ & $\mathrm{F}$ & E ssertial & 8 \\
\hline 75206 & PUNGER, OVERLOAD FOR B.J TOOLS & 572 & $\$ 783.64$ & $c$ & $\mathrm{~F}$ & Desired & 7 \\
\hline 75158 & ROLLER, DOOR - 7 58" TONO & 14 & $\$ 491.40$ & $\mathrm{c}$ & $s$ & E ssertial & 6 \\
\hline 75563 & SEAT, A.35TONG UNLOADER VAL YE & 19 & $\$ 84.36$ & $\mathrm{c}$ & $s$ & E ssertial & 6 \\
\hline 75036 & PIN, JANR ROLLER - 41/2" \& $51 / Z^{\prime \prime}-103 / 4 "$ TONG & 8 & $\$ 65.28$ & $\mathrm{c}$ & $\mathrm{s}$ & E ssertial & 6 \\
\hline
\end{tabular}

Figure 3. Sample output report 
The parts are arranged in descending order of their priority scores.

A ranked list is given in Table 9.

\begin{tabular}{|c|c|c|}
\hline Ranking & Part \# & Part Description \\
\hline 1 & 75557 & Body, Tong Door Interlock Valve \\
\hline 2 & 75014 & Stud, Cam - 14" Tong \\
\hline 3 & 75065 & Roller, Cam - 14" Tong \\
\hline 4 & 75012 & Housing, Mub - 5206 Bearing -7 5/8", 10 3/4" \& 14" Tong \\
\hline 5 & 75561 & Housing, A-35 Tong Unloader Valve \\
\hline 6 & 75558 & Spool. Tong Door Interlock Valve \\
\hline 7 & 75200 & Rod, Lock for BJ $350 \& 175$ \\
\hline 8 & 75220 & Rod, Lock - 500 Ton BJ \\
\hline 9 & 75037 & Roller Jaw - 13 3/8" \& 13 3/8" HT \& 10 3/4" \\
\hline 10 & 75035 & Pin, Jaw Hnge - 7 5/8", 10 3/4" \& 14" Tong \\
\hline 11 & 75195 & Pin, Yoke $-175,350 \& 500$ Ton BJ Tools \\
\hline 12 & 75318 & Stud, Cam - 36" Tong / 12" Casino Tong \\
\hline 13 & 75015 & Roller, Cam - 14" Tong \\
\hline 14 & 75319 & Roller, Cam - 36" Tong / 12" Casino Tong \\
\hline 15 & 75191 & Pin, Slip Hinge; BJ 175 Ton or B \& V 250 MT \\
\hline 16 & 75007 & Lug, Backing - 7 5/8", 10 3/4", 13 3/8", 21" Casino Tong \\
\hline 17 & 75562 & Poppet, A-35 Tong Unloader Valve \\
\hline 18 & 75206 & Plunger, Overload For BJ Tools \\
\hline 19 & 75158 & Roller, Door - 7 5/8" Tong \\
\hline 20 & 75563 & Seat, A-35 Tong Unloader Valve \\
\hline 21 & 75036 & Pin, Jaw Roller -4 1/2" \& 5 1/2" -10 3/4" Tong \\
\hline
\end{tabular}

Table 9. Ranking table

Our system suggests that those parts with higher priority scores are those which would be of more importance to the company and therefore should be produced in-house so as to have better control of it based on the production capacities and due dates. While those with lower priority scores are of lesser importance and may be considered for outsourcing within the allowable order constraints.

\section{Conclusions}

The case study is performed to develop an integrated inventory ranking procedure to determine make-or-buy decisions on the parts of an oilfield equipment company. A DSS called IRSIM is created to implement the procedure using MS Access database software.

Three different inventory classification techniques including ABC classification, FSN classification, and VED classification are integrated into IRSIM to combine both quantitative factors and qualitative factors to generate a ranked list. 
The integration of all three inventory classification techniques into a single system is a unique feature of this research. This is important as it provides a more inclusive, big picture view of the DSS for management's use in making business decisions.

The inventory ranking depends heavily on the weights given to the three classification methods. The VED ranking should have the most weight if vital parts can be easily identified. If the shortage of a part will shut down the entire process, then it should be given the highest priority over value and demand. The part's cost, or ABC classification, should have the second rank in the weight system. Lastly, the FSN classification can be used as a tie-breaker for highcost, vital parts in the process.

Our DSS is tested and verified by utilizing real world data, and the company has produced a list of parts to be made in-house. While we feel that the VED ranking should have the most weight, the management of the oil equipment company believes that the costly parts should be made in-house, so $A B C$ is given the highest weights. The decision reveals that the management may not feel very comfortable about their VED assignment. Other industries will generate different rankings if different priorities are used, indicating the need for a flexible DSS. This is very common in DSS applications.

Future enhancements to this research can be done in two areas. The inventory ranking procedure is based on three quantitative and qualitative factors as suggested by the company in our case study. Future research can consider other classification methods and other factors such as due dates and similar setups. The integration mechanism can also be enhanced to implement procedure to assign weights for the other factors. The IRSIM developed in this case study focuses on the make-or-buy decisions for one industry. The scope of IRSIM can be further extended to deal with other inventory management problem areas such as reorder strategies.

\section{References}

Atamtürk, A., \& Hochbaum, D.S. (2001). Capacity acquisition, subcontracting, and lot sizing. Management Science, 47, 1081-1100. http://dx.doi.org/10.1287/mnsc.47.8.1081.10232

Bed, N.K., \& Nagarur, N.N. (1994). An integrated decision support system for FMS: using intelligent simulation. International Journal of Production Research, 32(4), 951-965. http://dx.doi.org/10.1080/00207549408956981

Bhattachaya, A., Sarkar, B., \& Mukherjee, S.K. (2007). Distance-based consensus method for $A B C$ analysis. International Journal of Production Research, 45(15), 3405-3420. http://dx.doi.org/10.1080/00207540600847145 
Carr, A.S., \& Pearson, J.N. (1999). Strategically managed buyer-supplier relationships and performance outcomes. Journal of Operations Management, 17, 497-519. http://dx.doi.org/10.1016/S0272-6963(99)00007-8

Chase, R.B., Jacobs, F.R., Aquilano, N.J., \& Agarwal, N.K. (2006). Operations Management for Competitive Advantage. 11th Edition. New York, USA: McGraw Hill.

Chen, Y., Li, K., \& Liu, S. (2008). A comparative study on multi-criteria ABC analysis in inventory management. Systems, Man and Cybernetics, SMC 2008. IEEE International Conference, 3280-3285. http://dx.doi.org/10.1109/ICSMC.2008.4811802

Cohen, M.A., \& Ernst, R. (1988). Multi-item classification and generic inventory stock control policies. Production and Inventory Management Journal, 29(3), 6-8.

Ferrer, G. (2003). Yield information and supplier responsiveness in remanufacturing operations. European Journal of Operational Research, 149(3), 540-556. http://dx.doi.org/10.1016/S0377-2217(02)00454-X

Flores, B.E., \& Whybark, D.C. (1987). Implementing multiple criteria ABC analysis. Journal of Operations Management, 7(1), 79-84. http://dx.doi.org/10.1016/0272-6963(87)90008-8

Flores, B.E., Olson, D.L., \& Dorai, V.K. (1992). Management of Multicriteria Inventory Classification. Mathematical and Computer Modeling, 16(12), 71-82. http://dx.doi.org/10.1016/0895-7177(92)90021-C

Hadi-Vencheh, A. (2010). An improvement to multiple criteria ABC inventory classification. European Journal of Operational Research, 201(3), 962-965.

Hillier, M. (2002). Using commonality as backup safety stock. European Journal of Operational Research, 136(2), 353-365. http://dx.doi.org/10.1016/S0377-2217(01)00027-3

Hincapie, J., Lee, J., \& Emblom, W. (2011). Sensitivity Analysis on Inventory Classification Methods for Oilfield Equipment Industry. International Manufacturing Science and Engineering Conference, MSEC2011-50172, 145-153

Holmes, J. (1986). The organization and locational structure of production subcontracting. In A. Scott and M. Storper. Production, Work, Territory. Boston: Allen and Unwin. 80-106.

Holsapple, C.W., \& Whinston, A.B. (1996). Decision Support Systems: A Knowledge-based Approach. West Publishing Co., Minneapolis.

Jamshidi, H., \& Jain, A. (2008). Multi-criteria ABC inventory classification: With exponential smoothing weights. Journal of Global Business Issues, 2(1), 61-67.

Jeong, I.J., Leon, V.J., \& Villaboros, J.R. (2007). Integrated decision-support system for diagnosis, maintenance planning, and scheduling of manufacturing systems. International Journal of Production Research, 45(2), 267-285. http://dx.doi.org/10.1080/00207540600678896 
Kabir, G., \& Hasin, A., (2012). Multiple criteria inventory classification using fuzzy analytic hierarchy process. International Journal of Industrial Engineering Computations, 123-132

Kim, J., Chatfield, D., Harrison, T., \& Hayya, J. (2006). Quantifying the bullwhip effect in a supply chain with stochastic lead time. European Journal of Operational Research, 173(2), 617-636. http://dx.doi.org/10.1016/j.ejor.2005.01.043

Kirche, E., \& Srivastava, R. (2005). An ABC-based cost model with inventory and order level costs: A comparison with TOC. International Journal of Production Research, 43(8), 1685-1710.

Krause, D.R., Handfield, R.B., \& Scannell, T.V. (1998). An empirical investigation of supplier development: reactive and strategic processes. Journal of Operations Management, 17(1), 39-58. http://dx.doi.org/10.1016/S0272-6963(98)00030-8

Kumar, S., \& Wilson, J. (2009). A manufacturing decision framework for minimizing inventory costs of a configurable off-shored product using postponement. International Journal of Production Research, 47(1), 143-162. http://dx.doi.org/10.1080/00207540701477792

Lan, H., Ding, Y., \& Hong, J. (2005). Decision support system for rapid prototyping process selection through integration of fuzzy synthetic evaluation and an expert system. International Journal of Production Research, 43(1), 169-194. http://dx.doi.org/10.1080/00207540410001733922

Larson, S.E. (1980). Inventory systems and control handbook. New Jersey: Prentice-Hall.

Li, S., Murat, A., \& Huang, W. (2009). Selection of contract suppliers under price and demand uncertainty in a dynamic market. European Journal of Operational Research, 198(3), 830-847.

Mohebbi, E., \& Hao, D. (2006). When supplier's availability affects the replenishment lead time-An extension of the supply-interruption problem. European Journal of Operational Research, 175(2), 992-1008. http://dx.doi.org/10.1016/j.ejor.2005.06.015

Mukhopadhyay, S.K., Pathak, K., \& Guddu, K. (2003). Development of decision support system for stock control at area level in mines. IE(I) Journal-MN, 84(1), 11-16.

Nahmias, S., \& Demmy, W.S. (1981). Operating Characteristics of an Inventory System with Rationing. Management Science, 27(11), 1236-1245. http://dx.doi.org/10.1287/mnsc.27.11.1236

Ng, W.L. (2007). A simple classifier for multiple criteria ABC analysis. European Journal of Operational Research, 177, 344-353. http://dx.doi.org/10.1016/j.ejor.2005.11.018 
Partovi, F.Y., \& Anandarajan, M. (2002). Classifying inventory using artificial neural network approach. Computers and Industrial Engineering, 41, 389-404. http://dx.doi.org/10.1016/S03608352(01)00064-X

Petrovic, D., Petrovic, R., \& Rajat, R. (1998). Modeling and Simulation of a Supply Chain in an Uncertain Environment. European Journal of Operational Research, 109(2), 299-309. http://dx.doi.org/10.1016/S0377-2217(98)00058-7

Ramanathan, R. (2006). ABC inventory classification with multiple-criteria using weighted linear optimization. Computers and Operations Research, 33, 695-700. http://dx.doi.org/10.1016/j.cor.2004.07.014

Ronen, B., \& Trietsch, D. (1988). A decision support system for purchasing management of large projects. Operations Research, 36(6), 882-890. http://dx.doi.org/10.1287/opre.36.6.882

Saaty, T.L. (1980). The analytic hierarchy process. New York: McGraw-Hill.

Sadrian, A.A., \& Yoon, Y.S. (1994). A procurement decision support system in business volume discount environments. Operations Research, 42(1), 14-23. http://dx.doi.org/10.1287/opre.42.1.14

Walker, J. (2000). Decision support for the single-period inventory problem. Industrial Management \& Data Systems, 100(2), 61-67. http://dx.doi.org/10.1108/02635570010319693

Yang, G., Ronald, R., \& Chu, P. (2005). Inventory models with variable lead time and present value. European Journal of Operational Research, 164(2), 358-366. http://dx.doi.org/10.1016/j.ejor.2003.09.030

Yu, M.C. (2011). Multi-criteria ABC analysis using artificial-intelligence-based classification techniques. Expert Systems with Applications, 38(4), 3416-3421. http://dx.doi.org/10.1016/j.eswa.2010.08.127

Zeydan, M., \& Colpan, C. (2009). A new decision support system for performance measurement using combined fuzzy TOPSIS/DEA approach. International Journal of Production Research, 47(15), 4327-4349. http://dx.doi.org/10.1080/00207540802662870

Journal of Industrial Engineering and Management, 2014 (www.jiem.org)

Article's contents are provided on a Attribution-Non Commercial 3.0 Creative commons license. Readers are allowed to copy, distribute and communicate article's contents, provided the author's and Journal of Industrial Engineering and Management's names are included. It must not be used for commercial purposes. To see the complete license contents, please visit http://creativecommons.org/licenses/by-nc/3.0/. 